\title{
correspondence
}

\section{Rothschild: an antidote to panic}

SiR,- There are a number of inaccuracies or misrepresentations, doubtless unintentional, in the leading article $(30.11 .78)$ on my Dimbleby Lecture. I shall give a few examples: - "Lord Rothschild ... argued that we should develop a table of risks so that we could compare. say, the risk of our dying in an automobile accident with the risk of Baader-Meinhoff guerillas taking over (sic) the nuclear reactor next door." I specifically said that the risk of such a terrorist gang gaining entry to a nuclear power station was secret and therefore unknown.

- The leader claims I implied that viewers could not convert "probabilities from one form to another". The reverse is the case as evidenced by the visual example given, actually on a pocket calculator which was seen by the audience. The example was $109 \div 109=1$, $1,000.000 \div 109=9.200$. (Must I say, in

Nature, that $1.000,000 \div 109=9,174.3119$ ?)

- I was said not to have quoted "a

single error on the risks I enumerated"

The reason was quite simple: the $\mathrm{BBC}$ did not like references to confidence limits or intervals, although I spent some time in the lecture on the importance of what I call "tolerances". In addition. I said that " 1 in 100 is not exactly 1 in 100 in the world of risks, but, for example, probably somewhere between 1 in 95 and 1 in 105." If you had bothered to look at the printed version of the Dimbleby Lecture which was obtainable on 24 November, the day after the lecture was broadcast, you would have found references to

confidence limits under six of the seven tables in the lecture. Ranges were given in the other one, Table 6 . 'Therc are other misrepresentations which I did not expect in an editorial in Nature.

What is more important is that vour leader-writer has failed to understand the constraints imposed by talking about a highly complex and technical subject to 5 million people, the overwhelming majority of whom are laymen, in controdistinction to the few thousand who read Nature; and the restraints imposed by the BBC with their undoubted expertise.

I fear I am not competent to give a lecture on "the democracy of risk assessment", whatever you mean by that phrase. Let us hope your leader writer will soon give it, if only so that we know what it is.

As stated in the last but one paragraph of the lecture (p. 19), two of its main objects were to induce people to think about risks "for a minute or two", and "to compare the different risks around us." If I may quote myself in conclusion (p. 3): "Comparisons, far from being odious, are the best antidote to panic., In the editor's case the panic appears to be about the use of numbers.

ROTHSCHILD

N. M. Rothschild \& Sons Ltd.

New Court, St Swithin's Lane, EC4
SiR.--In your forceful editorial, you assert that the quantitative assessment of risks is not enough and that emotional reactions also deserve a role in decision-making. True, and indeed we live in a society where emotion is hardly likely to be under-represented in political decision-making. But emotional reactions are not necessarily and automatically decisive, and surely Lord Rothschild was merely concerned to get across the fact that such a thing as risk calculation exists and that it deserves a part in decision-making too. Many non-scientists don't know how risks are calculated, especially on an a priori basis; is it arrogant to draw attention to the fact that such calculations can be made?

One of the most intractable problems in the discussion of nuclear power (and genetic experiments, et hoc genus omne) is that the expert is the victim of a classic catch-22: he can only acquire expertise of certain kinds, it is implied, by working in the industry or science that is under attack, and that, it is asserted. automatically destroys his objectivity (and the non-objective cannot be a real expert). But if emotional bias is to be automatically presumed in the expert. then how is the undoubted emotional bias of the external attackers (ex hypothesi. they cannot be experts!) to be assessed? Does not that bias nullify the validity of the attack? In this connection it should be remembered that a recent public survey in Britain elicited the fact that a large majority of the public prefers to trust the technical judgment of the experts on nuclear power, intellectual prostitutes though they apparently are.

Emotional reaction to such things as nuclear reactors is a slippery basis for decision-making. I don't much like paying taxes. but I would hesitate to put that consideration too far ahead of dull calculations about the need to pay old agc pensions somehow. How is allowance to be made for the fact that fears can be whipped up for reasons which quite of ten are largely political? Is it to be accepted that certain forms of risk are psychologically intolerable however small they are, for inscrutable reasons, whereas others are cheerfully accepted even though not negligible? For instance, it is notable that there are no public attacks on the transport of liquefied natural gas. Rothschild quoted figures implying that this process is even safer than nuclear power, yet a large $L N G$ carrier bears explosive power equivalent to an atomic bomb. Though the LNG disaster involving a lorry in Spain indicates the destructive power of the fuel, the fact that no ship has blown up vet should not (on the analogy of the arguments applied to nuclear power) assuage the fears of those who live in harbour-towns where such ships arc unloaded. Why not? Could it be that such an attack would be politically embarrassing beceause most LNG comes from the Third World?
Even if, for argument's sake, one postulates that no one working in the muclear energy industry is to be trusted to give an honest opinion on contentious matters, it remains true that there exists a distinct group of experts, such as nuclear inspectors and medical radiation specialists. who can cast a cool and independent eve over some of the issues in dispute. For instance, Sir Edward Pochin, who is a medical professor, recently gave a lecture entitled "Why be Quantitative about Radiation Risk Estimates?" (National Council on Radiation Protection and Measurements, Washington, D.C. Lauriston Taylor Lecture No. 2. 1978). He makes a number of points in the special field of medical radiation protection which are very reminiscent of Lord Rothschild's and in the last part of his lecture he puts together some risk calculations from the UN OECD, the International

Commission on Radiological Protection. the US National Safety Council and the like (all, one would think, immaculately independent bodies) and concludes that the death risk from the total radiation exposure, from the entire uranium cycle, for an average citizen (including 'nuclear workers' in the average), in a country where one kilowatt electrical power per citizen comes from nuclear stations, is equivalent to the death risk from smoking one cigarette every two years. He adds that he recognises that relative acceptabilities of the two risks is another matter, but believes that "the numerical comparisons of this type do have a ccrtain value in letting radiation be seen in a proper context as one of the numerous potentially harmful components of the occupational, as of the general, environment. ..." The essential answer to your objection to Lord Rothschild's lecture, surely, is that it can only be beneficial to have context.

Tw'o other brief points should be made about your editorial. Firstly, you point out the special difficulty of assessing 'unknown risks'-risks of something that has never vet happened. like a serious reactor accident, or a major LNG ship disaster. But surely it is a very odd attitude to treat, by implication, something so safe that it has never yet gone seriously wrong over a period of vears, as more suspect (merely because no historica! risk estimate is feasible) than, say, coal-mining or deep-sca fishing? This implies that the more successful an industry is in minimising fatalities (and the nuclear power industry has, to date, a unique record), the larger the part that emotion (as distinct from facts) should play in assessing its desirability. Odd!

Finally: you make the intrinsically very powerful point that one cannot quantify the risk of the loss of some civil liberties if nuclear power expands. or, for that matter. quantify the emotional reaction to that eventuality. But who shall assess the risk of major social disorder occasioned by very serious energy shortages in future if nuclear power is stopped, and what numerical value would such a disamenity carry? 
That kind of argument always pulls in two directions.

Emotion is unavoidable in this kind of debate, and your readers will no doubt discern a smidgin of it in this letter. But in science, emotion should be the engine and reason should hold the steering-wheel and press the accelerator and brake. Risk analysis quite properly helps to guide the foot between those rival pedals. Robert C AHN $_{\text {An }}$

The University of Sussex,

School of Engineering and

Applied Science.

We did not wish to imply that emotional commitment characterised only one side of the nuclear debate-far from it-only that it was impossible to assess risks without taking such factors seriously. Further, the unknown risk referred to was the risk of failure of a commercial scale fast breeder reactor, for which there is no experience. $-E d$.

\section{Solar activity and influenza} the remarkable correlation between influenza $A$ viral antigenic shifts and peaks of the sunspot cycle as noted by R. E. Hope-Simpson (Nature 275, 86; 1978).

Ancient "cosmic and telluric theories" regarding influenza epidemics date as far back as the time of Hippocrates

(Thomson, D. \& Thomson, R. Ann. Pickett-Thom.son Res. Lab. 9, 257-261; 1933 and $10,1125-1140 ; 1934)$. Over half a century ago, F. G. Crookshank (Mil. Surg. 59, 284-290; 1926) defended the hypothesis that influenza pandemics and solar activity were correlated, and this possible relationship was further studied by M. Mygge (Acta Med. Scand. suppl. XXXII, 105-134; 1930). Since the discovery of a filtrable virus as the aetiological agent of influenza in the 1930 s, the notion of a solar-influenza association has been largely dismissed and forgotten.

Except for the pandemic of 1889 , the beginning dates of historical influenza pandemics in the 18th and 19th centuries (Mote, J. R. In: Viral and Rickettsial Diseases, Harvard University Press, 257-261, 1933), as well as pandemics and viral antigenic shifts in this century (Kilbourne, E. D. J. 'Amer. Med. Assoc. $237,1225-1228 ; 1977$ ), appear to have occurred in years of high sunspot number. From our present knowledge of influenza, it is not unreasonable to assume that these severe historical proportions were associated with major shifts in the influenza A haemagglutinin $(\mathrm{H})$ and neuraminidase $(\mathrm{N})$ surface antigens.

The mechanisms on how the solar cycle
SIR,-I would like to elaborate further on pandemics spreading rapidly to world-wide

can affect influenza pandemics may only be speculated upon at this time. The amount of ultraviolet light incident on the surface of the earth is increased in years of high sunspot activity (Pettit, $P$.

Astrophys. J. 75, 185-221; 1932), and this can conceivably accelerate the mutation rate of the influenza virus. The relationship between long-term cyclical fluctuations in meteorological and climatic conditions with the sunspot cycle remains controversial at this time. It is plausible. nevertheless, that during years of high solar activity, a more favourable ecological environment may exist for the genetic recombination of human and animal influenza viruses, with the emergence of new pandemic strains.

It is interesting to note that while the swine influenza virus (HswlNl) reappeared in 1976, its spread into pandemic or even epidemic proportions did not occur in this year of sunspot minimum. The resurfacing of the HINl subtype ("Russian flu") in December of 1977 was completely unexpected. The sunspot cycle was beginning its rapid ascent at that time.

It would not at all be surprising if a new strain of influenza A virus should emerge and dominate in the sunspot maximum years of the near future. On the other hand. perhaps what could only be expected from the elusive influenza virus is the unexpected.

US Public Health Service Hospital Baltimore, Md, USA

\section{Seveso: premature optimism}

SiR,-At the recent Seventh International Congress of Pharmacology in Paris, Dr G. Reggiani of the Hoffman-La Roche Medical Board presented a

communication on the clinical features of the July 1976 TCDD accident in Seveso. The Mario Negri Institute have closely followed many aspects of the investigations since then, and we feel some comment is necessary.

TCDD $(2,3,7,8$ tetrachlorodibenzo-pdioxine) is one of the most

powerful known toxic chemicals in animals, especially as regards its cumulative and delayed effects. So there cannot but be serious concern about the long term effects of the accident on man. regardless of the present impossibility of making any defensible prognosis

(S. Garattini Biomedicine 26, 28-29; 1977).

Since the accident, Hoffman-La Roche, which owns ICMESA through its subsidiary Givoudan, has been faced with many problems, of which public relations is certainly not the least. Its representatives have with every right denied false or exaggerated press reports such as charges that ICMESA had been secretly engaged in manufacturing

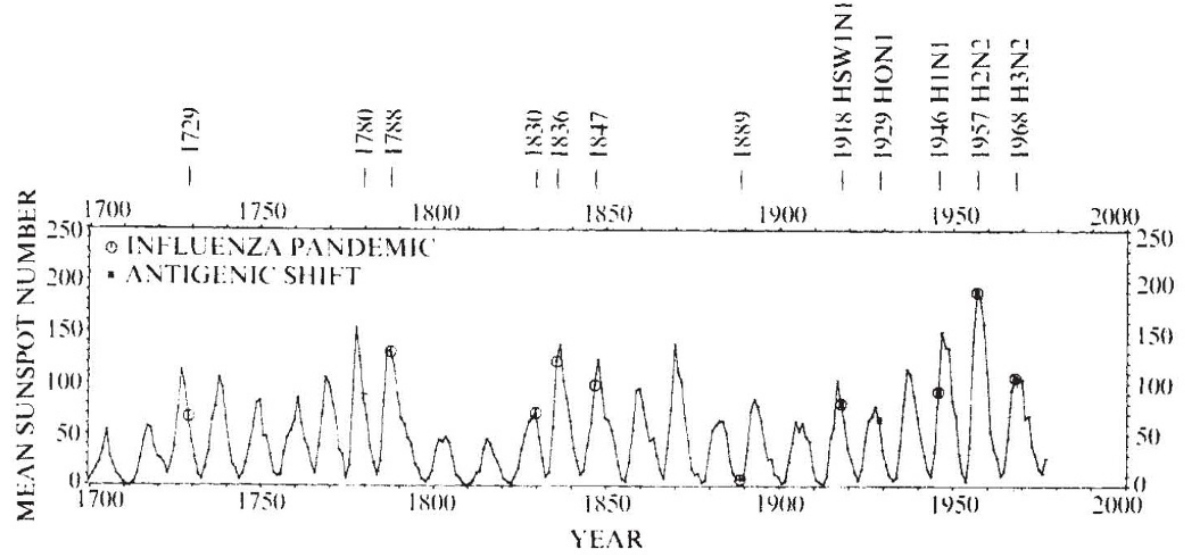

warfare chemicals. After a while, though. they began to comment optimistically on the potential health risks to people living in the polluted area. For example. Dr Reggiani noted that: "In the case of TCDD man seems to respond to a certain extent differently from other animal species ... " (J. Walsh Science 197, 1064-1067; 1977). There is no question that all efforts to minimise exposure of the residents in the disaster area should not be discontinued and we fervently hope Dr Reggiani's opinion proves right. But he seems to be rushing it somewhat by extending his increasingly sanguine attitude to retrospective evaluation.

His Paris communication was obviously biased by his desire to make little of the possible damage to human health. Thus he offered reassuring interpretations of findings such as those on chloracne, the typical skin lesion after TCDD exposure in humans, pointing out its "quick healing tendency" with the unsupported implication that it was quantitatively linked to exposure. He failed to mention its recurrence in people from widely scattered areas. Regardless of whether they were based on poorly reliable data such as observed rates of spontaneous abortion. Dr Reggiani confidently presented negative findings as strong evidence for the absence of TCDD induced pathology, with no criticism of the epidemiological methodology adopted or related problems deriving from the lack of adequate historical controls.

These points are evident from his abstract in the official volume (Abstract $n$. 2890, 953) which concludes: "The measures of protection of the population and prevention of further damage carried out at our request by the local authorities have avoided the severe injuries observed in previous similar accidents".

In view of this statement we must recall that the Seveso case cannot be compared with any previous accident involving TCDD because of 1) the uprecedently heavy contamination of inhabited areas. 2) the delay in recognising the nature of the accident and the resulting lag before protective measures were adopted, and 3 ) the significant amounts of TCDD persisting in the environment where people live. No mention of the TCDD risk was made to the local authorities before the disaster and even after it. Roche took almost two weeks to admit that TCDD had escaped from the plant.

It is unfortunate when someone takes advantage of a scientific meeting to present such misleading statements. People with no knowledge of the background and complexity of the Seveso case and the difficulty of epidemiological studies, may be led to accept the idea that thanks to Roche, all is well in Seveso now. This sounds outrageous to those who have already suffered distress from the disaster, apart from all considerations of feared future effects on health, which only time will reveal.

In addition and perhaps most relevant, our concern about Dr Reggiani's statement is of practical value. Everybody knows how difficult it is to motivate people to keep coming back for the controls needed for epidemiological studies. If the idea is spread around that there are no risks it will be difficult to collect long term data. No data available may well represent the best possible proof that no toxic effects occurred!

L. Manara, S. Garattini

Istituto di Ricerche Farmacologiche "Mario Negri", Milan, Italy 